\title{
SIMULAÇÃO DE CENÁRIOS ALTERNATIVOS DE USO DA TERRA EM UMA MICROBACIA UTILIZANDO TÉCNICAS DE MODELAGEM E GEOPROCE SSAME NTO(1)
}

\author{
R. E. MACHADO(2), C. A. VETTORAZZI (3) \& A. C. XAVIER ${ }^{(4)}$
}

\begin{abstract}
RESUMO
O modelo SWAT (Soil and Water Assessment Tool) foi aplicado na simulação de cenários alternativos de uso da terra na microbacia hidrográfica do Ri beirão dos Marins, em Piracicaba (SP), no biênio 1999/2000. Dois cenários foram simulados. No primeiro, o uso atual foi mantido numa faixa de mata ciliar de $30 \mathrm{~m}$ em toda a extensão dos cursos d'água e de $50 \mathrm{~m}$ ao redor das nascentes, de acordo com o Código F lorestal. No segundo cenário, como as pastagens ocupavam $30,9 \%$ da área da microbacia, nas encostas mais íngremes, com alto potencial erosivo, as áreas de pastagem foram substituídas por vegetação florestal. As simulações dos dois cenários foram comparadas com as condições do cenário atual em termos de produção de sedimentos. Os cenários geraram diferentes padrões espaciais da produção de sedimentos. Uma redução de 94,0 \% na produção de sedimentos foi obtida com a substituição da pastagem por vegetação nativa (cenário 2). No cenário 1, a redução foi de 10,8\%. Esses resultados evidenciam a necessidade de tratar a pai sagem em bacias hidrográficas de forma global, identificando as "áreas sensíveis ambientalmente", onde são necessárias práticas de controle dos processos erosivos e não somente práticas de proteção dispensada aos cursos d'água por meio da mata ciliar.
\end{abstract}

Termos de indexação: modelos de simulação, poluição difusa, sedi mentos, SI G'S, SWAT.

(1) Recebido para publicação em fevereiro de 2002 e aprovado em maio de 2003.

(2) Engenheiro Agrícola, Doutor em Irrigação e Drenagem, Departamento de Engenharia Rural, Escola Superior de Agricultura "Luiz de Queiroz" - DER/ESALQ/USP. Caixa Postal 09, CEP 13418-900 Piracicaba (SP). E-mail: remachad@carpa.ciagri.usp.br

(3) Professor Doutor, Departamento de Engenharia Rural, ESALQ/USP. E-mail: cavettor@carpa.ciagri.usp.br

(4) Engenheiro Agrícola, Doutor em Irrigação e Drenagem, DER/ESALQ/USP. E-mail: acxavier@carpa.ciagri.usp.br 


\title{
SUMMARY: ALTERNATIVE SCENARIO SIMULATION OF LAND USE IN A WATERSHED THROUGH GEOPROCESSING AND MODELING TECHNIQUES
}

\begin{abstract}
The model SWAT (Soil and Water Assessment Tool) was used to simulatealternative scenarios of land usein Ribei rão dos Marins watershed, in Piracicaba, State of São Paulo, Brazil, for the biennial period 1999/2000. Two scenarios were simulated. The first one (scenario 1) was based on the current land use except for the introduction of a continuous riparian buffer of $30 \mathrm{~m}$ along the drainage network and of $50 \mathrm{~m}$ around the springs, in accordanceto Brazil's environmental legislation. In thesecond (scenario 2) thesteepest sl opes (30.9\% of thewatershed area) with high erosivepotential, covered by pasture, weresubstituted by native forest. The two si mulated scenarios were compared to the current one in relation to sediment yield. Thescenarios brought forth different spatial patterns of sediment yiel d. A reduction of $94,0 \%$ in sediment yield was obtained by the substitution of pasture with native vegetation (scenario 2), and of $10.8 \%$ in scenario 1 . These results showed that it is necessary to manage landscape aspects of watersheds comprehensively, identifying the environmentally most sensitive areas, mainly in relation to erosion, instead of protecting only the riparian areas.
\end{abstract}

Index terms: simulation models, non-point source pollution, sediment, GIS, SWAT.

\section{NTRODUÇÃO}

O conhecimento dos efeitos da variação no uso da terra sobre o movimento de sedimentos e água através da bacia hidrográfica é muito importante para a tomada de decisões sobre o manejo de uso da terra (Kuhnle et al., 1996).

Model os matemáticos sãolargamenteempregados na predição do processo erosivo, tanto para o planejamento conservacionista (preventivo) como para seu controle (J ames \& Gurges, 1982). O objetivo da modelagem é, então, compreender melhor os processos que ocorrem em um sistema como uma bacia hidrográfica (Fohrer et al., 2001).

A principal vantagem da aplicação de modelos reside na possibilidade do estudo de vários cenários diferentes e deforma rápida, muitos deles ainda não explorados em experimentos reais. Outra importante vantagem da utilização de simulação de cenários está associada a seu baixo custo. $\mathrm{Na}$ maioria das aplicações, o custo de executar um programa computacional é muitas ordens de magnitude menor do que o correspondente custo relativo à investigação experimental. Esse fator adquire maior importância à medida queo problema real estudado apresenta maiores dimensões e complexidade (como uma bacia hidrográfica), além dos custos operacionais mais el evados relativos às pesquisas de campo (Pessoa et al., 1997).

A maior limitação ao uso de modelos é a dificuldade em trabalhar grande quantidade de dados que descrevem a heterogeneidade dos sistemas naturais. Por essas razões, Sistemas de I nformações Geográficas (SI G's) são empregados na criação do banco de dados desses model os.
Por ser o uso desses model os limitado pela necessidade de dados espaciais e por proporcionarem os SIG's grande facilidade em manipular esses dados, a união dessas duas tecnologias representa um importante passo para o manejo de bacias hidrográficas. Com esta combinação, é possível não só visualizar cenários passados atuais, mas também simular cenários futuros com baixo custo e deforma rápida (Grigg, 1996).

Nesse contexto, este trabalho objetiva simular cenários alternativos de uso e ocu pação da terra na microbacia hidrográfica do Ribeirão dos Marins (Piracicaba, SP), por meio da integração SWATArcView, e compará-los quanto à produção de sedimentos com o cenário de uso atual, para o biênio 1999/2000.

\section{MATERIAL E MÉTODOS}

A área selecionada para este estudo foi a microbacia hidrográfica do Ribeirão dos Marins (MHRM), afluente do rio Piracicaba, localizada no município de Piracicaba, estado de São Paulo, entre as coordenadas UTM (Universal Transversa de Mercator) 216.000, 226.000, 7.470.000 e 7.488.000 m $\mathrm{N}$ (Fuso $22 \mathrm{~S}$, meridiano central $51^{\circ} \mathrm{W}$ ), com uma área aproximada de 5.973 ha (Figura 1).

As informações do uso da terra foram obtidas a partir de uma imagem do satélite SPOT datada de julho de 1998. Quatro classes predominantes de uso da terra foram identificadas. A cultura da cana-deaçúcar ocupa a maior parte da microbacia (56,2 \%), nas áreas de menor declive, enquanto as encostas mais íngremes são ocupadas com pastagem (30,9\%). 


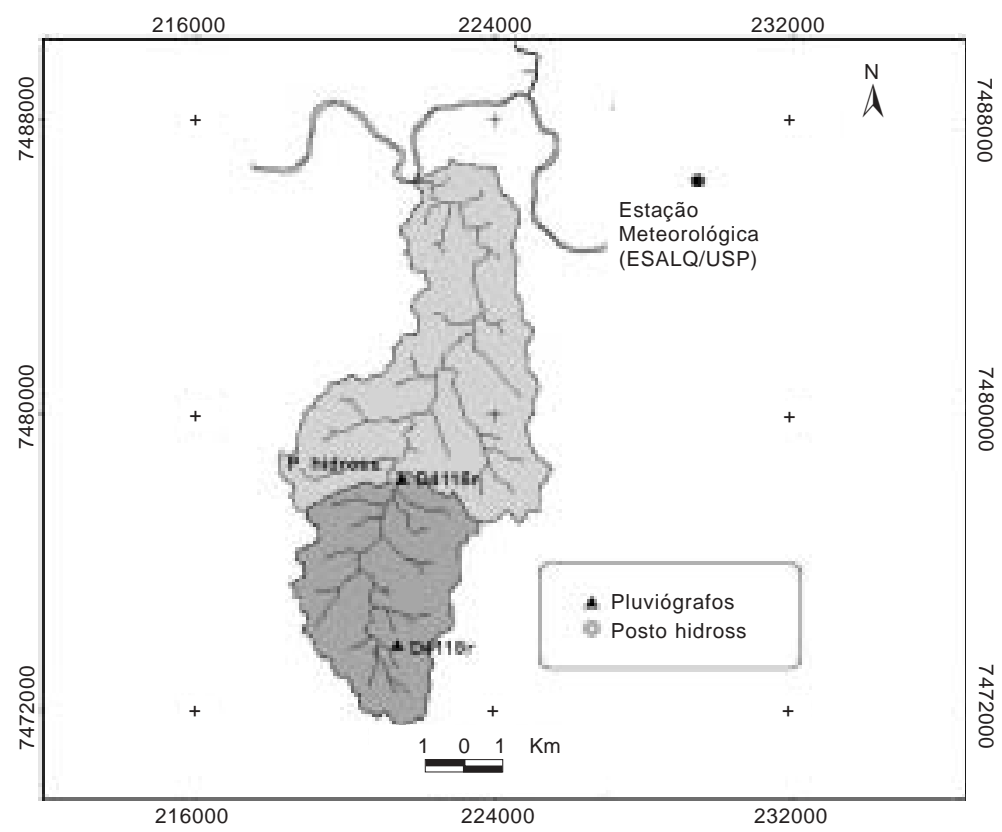

Figura 1. Microbacia do Ribeirão dos Marins, com a indicação da localização do posto hidrossedi mentométrico e dos pluviógrafos.

A vegetação original, quase inexistente com a evolução do uso e ocupação do solo na área de estudo, encontra-se apenas em algumas grotas e nas margens do ribeirão dos Marins (11,6\%). A área urbana ocupa $2,02 \%$ e está localizada no terço inferior da microbacia. Os tipos de solo dominantes são os Litólicos (41\%) e os Podzólicos (58 \%) (Machado \& Vettorazzi, 2003).

A partir dos resultados obtidos por Machado \& Vettorazzi (2003), foram feitas simulações de cenários alternativos de uso da terra, utilizando o model o SWAT interfaceado ao SI G ArcView, com o objetivo de verificar o efeito dos cenários sobre a produção de sedimentos (sedimentos transportados das sub-bacias para o canal principal durante o passo de tempo) na microbacia em estudo. O trabalho avaliou a distribuição espacial da produção de sedimentos na microbacia hidrográfica do Ribeirão dos Marins, por meio da integraçãoSWAT-ArcView, e analisou comparativamente os resultados gerados pelo modelo quanto à produção mensal de sedimentos com os dados observados em um posto hidrossedimentométrico local izado no terço superior da mi crobacia, no período de 1999 a 2000 (Figura 1). U ma descrição compl eta do método empregado para a simulação da produção de sedimentos na microbacia do Ribeirão dos Marins foi apresentada em Machado \& Vettorazzi (2003).

Duas simulações foram feitas com o objetivo de exemplificar a aplicação e a integração de model os hidrológicos e de qualidade de água com SIG para avaliar opções de uso da terra em microbacias hidrográficas. Essa integração permiteque se varie somente o Plano de Informação (PI) de uso e ocupação da terra. Os efeitos da variação no uso da terra sobre a produção de sedimentos foram avaliados em comparação com a produção de sedimentos do uso atual (Figura 2a). Os cenários avaliados foram:

- cenário 1: Uso da terra atual, mas atendendoa duas determinações do Código Florestal. O Código Florestal vigente, Lei $\mathrm{n}$ 0 4771, de 15 de setembro de 1965, modificada pelas Leis no 7803/89 e 7875/ 89, estabelece legalmente uma faixa de área que deve ser protegida ao redor dos corpos d'água e nascentes. Essa faixa deárea varia de acordo com a largura dos rios e engl oba as matas ciliares. A largura mínima de proteção a florestas e demais formas de vegetação natural, situadas ao longo dos cursos d'água, consideradas como Áreas de Preservação Permanente (APP's) é de 30 m (para cursos d'água com largura de até $10 \mathrm{~m}$ ) e, nas nascentes, ainda que intermitentes, e nos "ol hosd'água", em um raio de $50 \mathrm{~m}$. Assim, criou-se um "buffer" na rede de drenagem com esses valores, sobrepondo-o à imagem de uso atual (Figura 2b).

- cenário 2: Outra determinação do Código F lorestal vigente considera de preservação permanente as florestas e demais formas de vegetação natural situadas nas encostas ou partes destas com declividade superior a $45^{\circ}(100 \%)$ na linha de maior dedive. Comona mi orobacia a cana-de-açúcar é cultivada nas áreas de menor declividade, enquanto as pastagens ocupam as encostas mais íngremes, em geral mal manejadas e localizadas em sol os litólicos, nesse cenário, as áreas ocupadas por pastagem foram integralmente substituídas por vegetação florestal nativa (Figura 2c). 
(a)

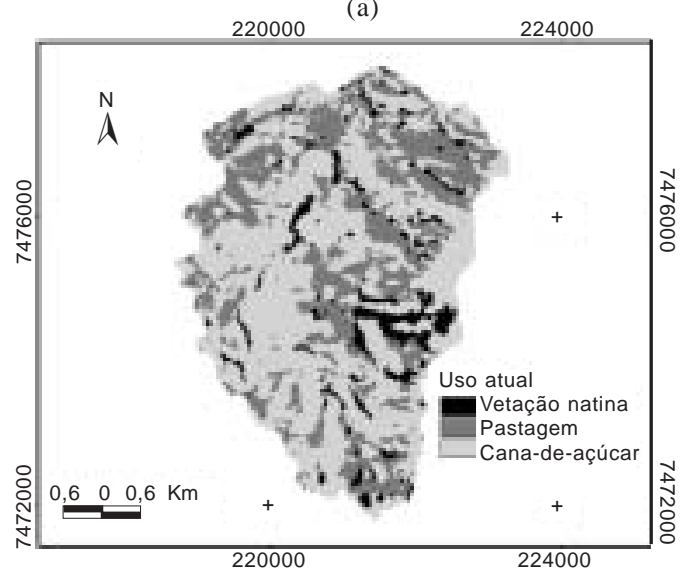

(b)

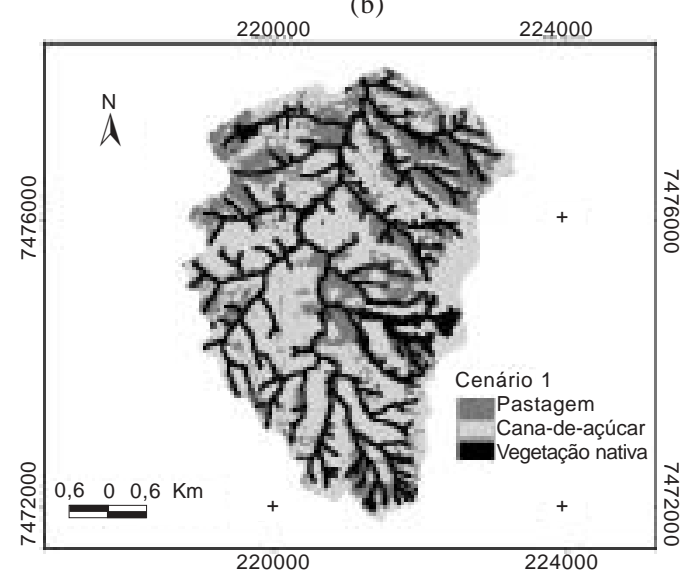

(c)

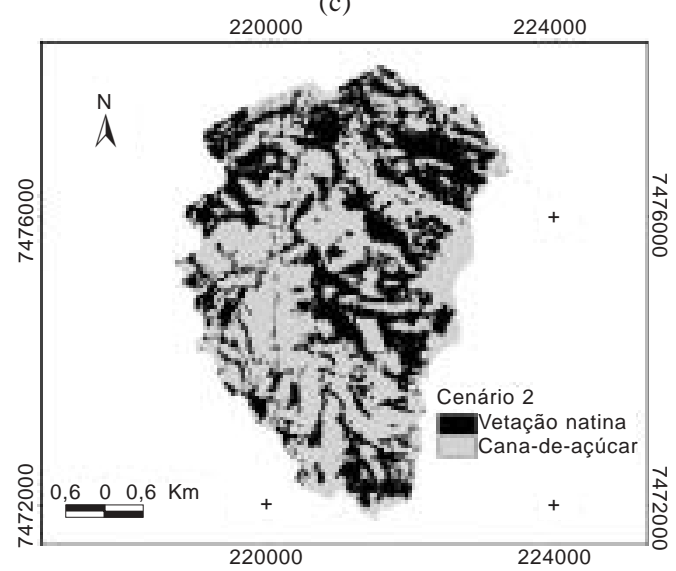

Figura 2. Uso da terra na microbacia do Ribeirão dos Marins para o uso atual e para os dois cenários simulados.

\section{RESULTADOS E DISCUSSÃO}

No quadro 1 são apresentadas as áreas totais e relativas de ocupação de cada cobertura da terra na MHRM, para o cenário de uso atual e para os outros dois cenários, até o posto hidrossedimentométrico. Com a passagem do cenário atual para o cenário 1, há uma diminuição nas áreas ocupadas por canade-açúcar $(-7,74 \%)$ e pastagem $(-10,83 \%)$ e um ganho na área ocupada por vegetação nativa
(+18,57\%). No cenário 2, a área ocupada por cana-deaçúcar permaneceu inalterada. A área ocupada com vegetação nativa passou a ocupar $41,23 \%$ da bacia contra os 8,10 \% do cenário deuso atual, já que passou a ocupar toda a área antes ocupada por pastagem.

Comparando os resultados das simulações entre o cenário de uso atual e os outros dois cenários, o model o diminui a predição da perda desolos sobrea mai oria das sub-bacias no cenário 1 . No cenário 2, os resultados da produção de sedimentos foram

Quadro 1. Uso e ocupação da terra para os três cenários (uso atual e os 2 cenários) até o posto hidrossedimentométrico

\begin{tabular}{lcccrrrr}
\hline Uso da terra & \multicolumn{2}{c}{ Uso atual } & \multicolumn{2}{c}{ Cenário 1 } & & Cenário 2 \\
\hline & \multicolumn{1}{c}{ ha } & $\%$ & ha & $\%$ & ha & $\%$ \\
Cana-de-açúcar & $1.310,37$ & 58,78 & $1.137,77$ & 51,04 & 1310,23 & 58,78 \\
Pastagem & 738,15 & 33,12 & 496,86 & 22,29 & - & - \\
Vegetação nativa & 180,76 & 8,10 & 594,65 & 26,67 & 919,05 & 41,23 \\
Total & $2.229,28$ & 100,00 & $2.229,28$ & 100,00 & $2.229,28$ & 100,00 \\
\hline
\end{tabular}


ainda menores. No cenário de uso atual, a produção de sedimentos simulada até o posto hidrossedimentométrico variou a partir de 0,00 a 1,28 t ha-1, no período analisado, com uma média de $0,11 \mathrm{t} \mathrm{ha}^{-1}$. No cenário 1 , quando a vegetação nativa foi consi derada em toda a extensão da redededrenagem e nas nascentes, a produção de sedimentos variou de 0,00 a $0,83 \mathrm{t} \mathrm{ha}^{-1}$, com um valor médio de 0,10 t ha $^{-1}$. No cenário 2, com a substituição por vegetação nativa nas áreas ocupadas por pastagens, a produção média foi de $0,01 \mathrm{t} \mathrm{ha}^{-1}$ por ano, com um valor máximo observado de 0,05 t ha-1 (Figura 3).

No cenário 1 , a diminuição na produção de sedimentos foi de 10,8\%, comparativamente ao cenário de uso atual nos dois anos de simulação, enquanto, no cenário 2, a diminuição foi de $94,0 \%$, comparativamente ao cenário de uso atual. I sso foi devido ao diferente fator C (USLE) associado com o tipo de cobertura atual. Nesse cenário, a perda de solo ficou abaixo da perda desolotolerável para todos os tipos de sol o que, segundo Leiz \& Leonardos (1977), foi de 7,9 t ha-1, para o Podzólico, e de 4,2 t ha-1 ${ }^{-1}$, para o Litólico.

A mudança do uso da terra nas áreas ocupadas por pastagem por vegetação nativa diminuiu a exposição dos solos mais susceptíveis à erosão. Desse modo, o uso dos sol os Litól i cos ePodzól icos para fins agrícol as foi reduzido. Segundo Brooks et al. (1991), o pastoreio em condições adequadas normalmente não aumenta a quantidade de sedi mentos nos corpos d'água após chuvas intensas; mas o pastoreio intensivo, em terrenos inclinados e sol os frágeis, pode causar sérios problemas erosivos. Ainda segundo os autores, a produção de sedimentos aumenta quando a área ripária também é utilizada como pastagem, o que leva à erosão das margens

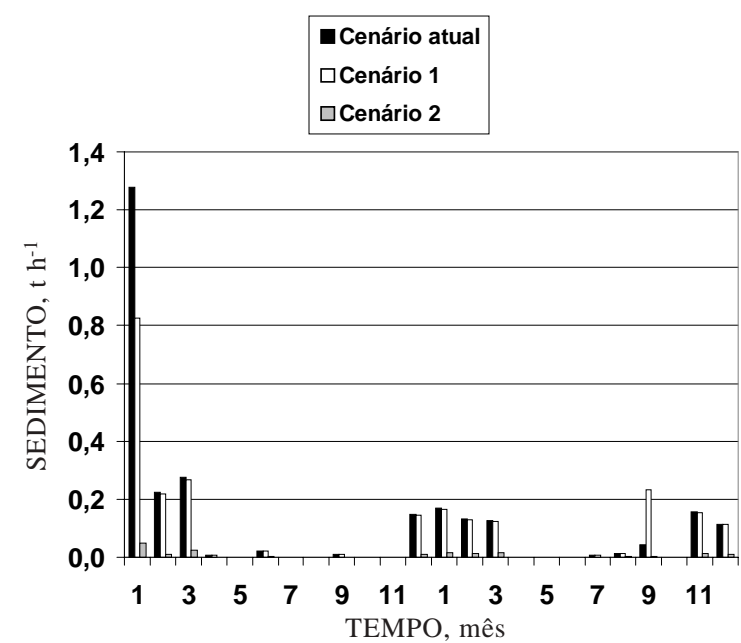

Figura 3. Comparação da variação temporal da produção de sedi mentos entre os três cenários no posto hidrossedimentométrico localizado na MHRM. dos rios e à deposição dos sedimentos diretamente no leito. A erosão proveniente das áreas cultivadas responde por cerca de $38 \%$, enquanto a erosão proveniente depastagens respondepor cerca de $26 \%$ dos sedimentos que atingem os corpos d'água nos EUA (USDA, 1991).

O impacto total do cenário 2 na redução de sedimentos é muito maior do que o do cenário 1. Entretanto, as diferentes respostas, comparando-se 2 e 1, não sãolineares, princi palmente pela diferente posição geográfica ocupada pela vegetação nativa nos cenários 1 e 2. Acumulando o efeito sobre o período de dois anos, infere-se que o cenário 2 reduziu em $82,6 \%$ a produção de sedimentos em relação ao cenário 1. Aparentemente, o efeito da variação do uso da terra no cenário 2 causou menos erosão e muito mais deposição do que a variação do uso atual para o cenário 1. A distribuição espacial da produção de sedimentos para o mês de janeiro de 1999 (o mês com maior produção de sedimentos), considerando o uso atual e os outros 2 cenários, é apresentada na figura 4.

Comparando o cenário de uso atual com o cenário 2, é esperado que a vegetação nativa possa diminuir a erosão, uma vez que altera diretamente os parâmetros de infiltração e especialmente a proteção dada ao solo contra o impacto direto das gotas de chuva eaumento da rugosi dade superficial . Segundo Larson (1997), a rugosidade superficial é um importante fator na redução do escoamento superficial e, conseqüentemente, no transporte de sedimentos.

Como o tipo de cobertura do solo que passou a predominar nas áreas íngremes foi a vegetação florestal nativa, éfácil compreender a atuação desse tipo de cobertura não somente como barreira aos sedimentos, mas também como áreas de baixíssimo nível de produção de sedimentos. Quando o escoamento superficial passa de uma área cultivada com cana-de-açúcar para a área ocupada com a vegetação nativa, ocorre uma diminuição na velocidade do fluxo pela rugosidade superficial, bem como maior resistência da vegetação. A diminuição da velocidade, por sua vez, resulta na diminuição da capacidade de transporte de sedimentos, impedindo que estes cheguem à rede de drenagem por meio da deposição antecipada de sedimentos. Os poluentes adsorvidos aos sedimentos são também aí depositados (Larson, 1997).

Contudo, no cenário 1, ao longo do Ribeirão dos Marins, considerando estar a mata ciliar em bom estado de preservação, infere-se que esta atuaria como uma barreira de proteção aos sedimentos, principalmente no sentido de reduzir a velocidade de escoamento e, conseqüentemente, agir como um filtro, retendo parte dos sedimentos.

No entanto, ainda existem dúvidas em relação à eficiência das florestas ripárias como filtros de poluição difusa para outras regiões, já que a maior 




Figura 4. Distribuição espacial da produção de sedimentos no mês de janeiro de 1999, na microbacia hidrográfica do Ribeirão dos Marins, para os cenários: (a) uso atual; (b) cenário 1; (c) cenário 2. parte dos estudos foi realizada para bacias do Cinturão do Milho e Nordeste dos Estados U nidos, sendo ainda necessários dados mais detal hados sobre sua eficiência em outras condições ambientais (USDA, 1991).

A legislação brasileira adota uma largura mínima de acordo com a largura do curso de água. Esse tipo de del imitação não considera as diferenças regionais (p.e., clima, condições da superfície, relevo, solos, atividades no entorno), o que pode não garantir a eficiência necessária como barreira de retenção de sedimentos.

Apesar de toda essa discussão, a mata ciliar oferece uma valiosa proteção às margens dos rios, habitat da vida animal, a proteção de ecossistemas aquáticos adjacentes econstitui um dos fatores que, em conjunto com outras práticas conservacionistas, compõem o manejo adequado da bacia com a finalidade de garantir a quantidade equalidade dos recursos hídricos.

Dentro dos limites de uma bacia hidrográfica, podem ocorrer áreas que requerem maior atenção, seja por estarem local izadas em terrenos íngremes, seja por serem essas áreas constituídas de solos altamente susceptíveis à erosão, ou a combinação de ambos os fatores. Nas bacias hidrográficas em que ocorre essetipo de área, considerada como “área sensível ambientalmente" (Ndubisi et al., 1995), um meio efetivo de diminuir a intensidade da produção de sedimentos é fazer com que esses locais fiquem fora da agricultura intensiva esejam manti dos como Áreas de Preservação Permanente. Assim, os programas de conservação de sol o eágua podem ser mais eficientes, em vez de considerar somente as matas ciliares, desde as nascentes até a foz, como único sistema de proteção dos recursos hídricos, o que ficou demonstrado neste estudo. Práticas agrícolas intensivas são usualmente associadas a altos níveis de uso de fertilizantes, resultando em poluição potencial das águas superficiais e subterrâneas (poluição de origem difusa).

As simulações de cenários indicaram que as variações no uso da terra podem diminuir a produção de sedimentos na MHRM. Neste estudo, foram modelados os possíveis efeitos da vegetação florestal nativa na produção de sedimentos.

A principal vantagem do uso dos SIG's para modelar a perda de solos é a sua habilidade para analisar a variabilidade espacial do potencial de erosão na microbacia, com base na influência de fatores, tais como: relevo, tipo de solo, uso da terra, precipitação, dentre outros.

\section{CONCLUSÕES}

1. Os resultados evidenciaram a necessidade de setratar a paisagem em bacias hidrográficas de uma 
forma global, identificando as "áreas ambientalmente sensíveis", onde são necessárias práticas de controle dos processos erosivos ou mudanças de uso da terra, e não somente a proteção dispensada aos cursos d'água por meio da mata ciliar.

\section{LITERATURA CITADA}

BROOKS, K.N.; FFOLLIOTT, P.F.; GREGERSEN, H.M. \& THAMES, J.L. Hydrology and the management of watersheds. Ames, I owa StateUniversity Press, 1991. 392p.

ELMORE, W. \& BESCHTA, R.L. Riparian areas: perceptions in management. Rangelands, 9:290-265, 1987.

FOHRER, N.; HAVERKAMP, S.; ECKHARDT, K. \& FREDE, G. Hydrologic response to land use changes on the catchment scale. Phys. Chem. Earth, 26:577-682, 2001.

GRIGG, N.S. Water resources management: principles, regulations, and cases. New York, McGraw-Hill Book, 1996. 540p.

J AMES, L.D. \& GURGES, S.J . Selection, calibration and testing of hydrologic models. In: HAAN, C.T., ed. Hydrologic modeling of small watersheds. St. J oseph, ASAE, 1982. p.437-472.
KUHNLE, R.A.; BINGER, R.L.; FOSTER, G.R. \& GRISSINGER, E.H. Effect of land use changes on sediment transport. Water Res. Res., 32:3189-3196, 1996.

LARSON, W.E.; LINDSTROM, M.J . \& SCHUMACHER, T.E. The role of severe storms in soil erosion: a problem needing consideration. Soil Water Conser., 52:90-95, 1997.

LEINZ, V. \& LEONARDOS, O.H. Glossário geológico. 2.ed. São Paulo, Companhia Editora Nacional, 1977. 236p.

MACHADO, R.E . \& VETTORAZZI , C.A. Simulação da produção de sedimentos para a microbacia hidrográfica do ribeirão dos Marins, SP. R. Bras. Ci. Solo, 4:735-741, 2003.

NDUBISI, F.; DE MEO T. \& DITTO, N.D. Environmentally sensitive area: a template for developing greenway corridors. Landscape Urban Plan., 33:159-177, 1995.

PESSOA, M.C.P.Y.; LUCHIARI, A.J .; FERNANDES, E.N. \& LIMA, M.A. Principais model os matemáticos esimuladores utilizados para análise de impactos ambientais das atividades agrícolas. J aguariúna, EMBRAPA/CNPMA, 1997. 83p. (EMBRAPA. CNPMA. Documentos, 8)

U.S. DEPARTMENT OF AGRICULTURE - USDA. Riparian forest buffers: function and design for protection and enhancement of water resources. Pennsylvania, 1991. 24p. 